\title{
FREE GINGIVAL AUTOGRAFT FOR AUGMENTATION OF KERATINIZED TISSUE AND STABILIZATION OF GINGIVAL RECESSION- 2 CASE REPORTS
}

\author{
Hemant Kumar Gupta, ${ }^{1}$ Sangeeta Aggarwal, ${ }^{2}$ Ruby Singla ${ }^{3}$, Sumit Kochhar ${ }^{4}$, Dr Sukhvinder Kaur ${ }^{5}$ \\ ${ }^{1}$ Prof. \& Head, Department of Periodontics, Adesh Institute of Denal Sciences and Hospital, Punjab, India \\ ${ }^{2}$ SMO, Department of Conservative Dentistry and Endodontics, Government Dental College \& Hospital, Punjab, India \\ ${ }^{3}$ Senior Lecturer, Department of Periodontics, Adesh Institute of Denal Sciences and Hospital, Punjab, India \\ ${ }^{4}$ Reader, Department of Periodontics, Adesh Institute of Denal Sciences and Hospital, Punjab, India \\ ${ }^{5}$ Lecturer, Department of Periodontics, Adesh Institute of Denal Sciences and Hospital, Punjab, India
}

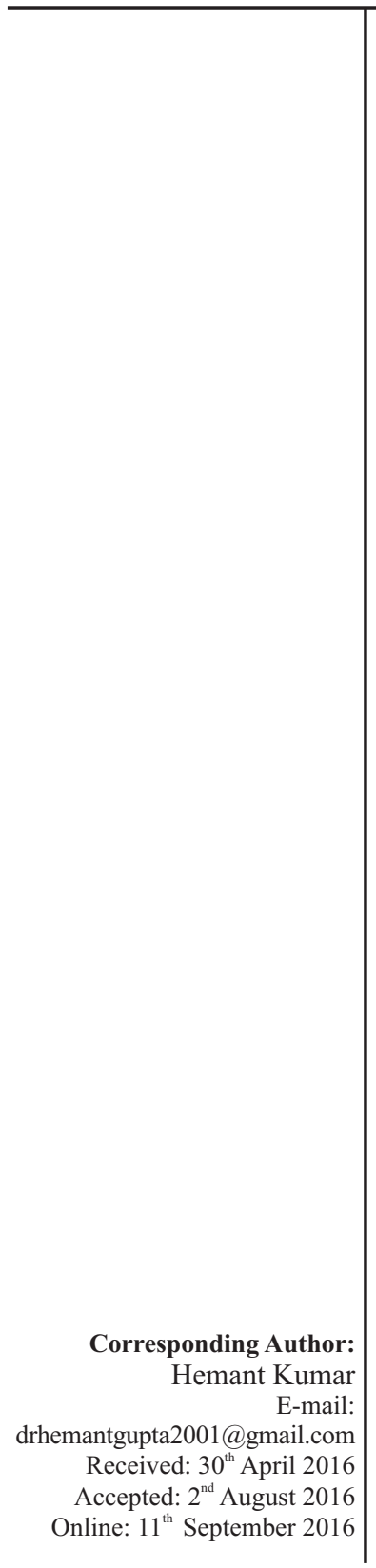

\begin{abstract}
In the current practice of periodontics, clinicians are faced with the challenge of not only addressing biological and functional problems present in the periodontium, but also providing therapy that results in acceptable aesthetics. The presence of mucogingival problems and gingival recession around anterior, highly visible teeth exemplifies a situation in which a treatment modality that addresses both biological and aesthetic demands is required from the therapist. Periodontal plastic surgery procedures are performed to resolve these mucogingival problems. This paper presents two cases of gingival recession (Miller's class I and class II ) successfully treated with complete root coverage by free gingival autografts.
\end{abstract}

Key words: Gingival Recession, Free Gingival Auto Graft

\section{INTRODUCTION}

Gingival recession is defined as "Displacement of soft tissue margin apical to the cemento-enamel junction with exposure of the root surface. ${ }^{1}$ In populations maintaining high standards of oral hygiene, loss of attachment and marginal tissue recession are predominantly found on buccal surfaces. ${ }^{2}$ Gingival recessions are often associated with genetically determined anatomic situations like an insufficient amount of keratinized gingiva, frenal pull, tooth malposition, dehiscence and fenestration of facial bone but the most common cause of the recession defects is abrasive and traumatic toothbrushing. ${ }^{3} \quad$ American academy of periodontology has suggested indications for gingival augmentation, namely: ${ }^{4}$
1. To prevent soft tissue recession in the presence of alveolar bone dehiscence during orthodontic tooth movement

2. To halt progressive marginal gingival recessions.

3. To improve plaque control and patient comfort around teeth and implants.

4. To increase the insufficient dimension of gingiva in conjunction with fixed or removable prosthetics dentistry.

Several techniques have been used, including formation of a free gingival graft (FGG), laterally positioned flap (LPF) or coronally advanced flap (CAF) as well as guided tissue regeneration (GTR) and sub-epithelial connective tissue grafts (SCTG) alone or in combination with other techniques. Free gingival autograft is one of the most 
common techniques used for gingival augmentation apical to the area of recession. This technique accomplishes the following objectives: enhances plaque removal around the gingival margin, reduces gingival inflammation and improves esthetics. ${ }^{5}$ Some studies have reported stability of gingival margin and reduction of recession after free gingival augmentation procedure. ${ }^{6}$ This paper presents two cases of gingival recession treated by free gingival graft.

CASE 1. A 29 years old female patient reported to the department of Periodontology, Adesh Dental College and Hospital, Bathinda with a chief complaint of unesthetic appearance of her front, lower teeth (Figure 1). Her systemic problems were ruled out before surgery. The patient's oral hygiene was fair. There was no other periodontal concern other than Miller's class I recession of tooth \#31 and \#41, measuring 4mm each. Presurgical therapy included patient motivation, education and non surgical periodontal therapy. After the patient's consent, it was decided to treat the site by free autogenous gingival grafting to achieve root coverage and simultaneously increase the attached gingiva as well as vestibular depth.

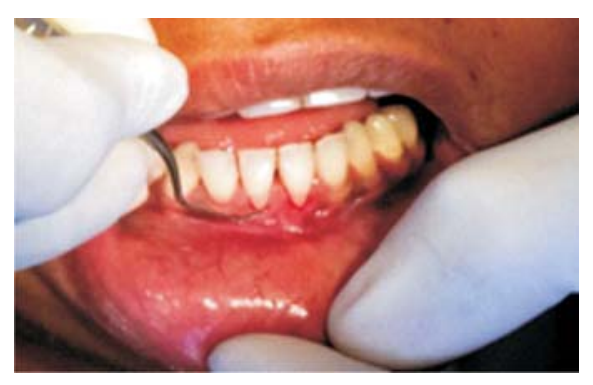

Figure 1: Class I gingival recession

CASE 2. A 23 years old female patient reported to the department of Periodontology, Adesh Dental College and Hospital, Bathinda with a chief complaint of sensitivity and root exposure in a lower front tooth (Figure 2). Her general health condition was good, did not take any medications, had no known allergies and was nonsmoker. Clinical evaluation revealed gingival recession on buccal surface of 41 , extending $7 \mathrm{~mm}$

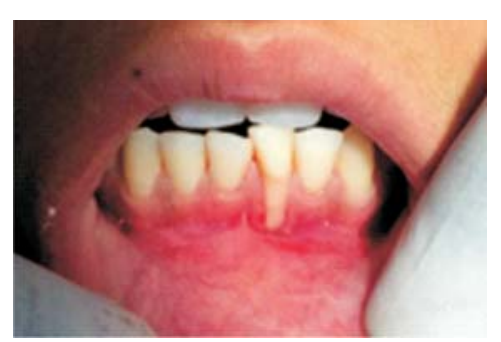

Figure 2: Class II gingival recession

apical to the CEJ and a narrow zone of attached gingiva. The patient's oral hygiene was fair. There was no other periodontal concern other than Miller's class II recession of tooth $\# 41$. Presurgical therapy included patient motivation, education, plaque control instruction, scaling and root planing. Root canal treatment was also completed because of acute sensitivity with respect to that tooth. After the patient's consent, it was decided to treat the site by free autogenous gingival grafting to achieve root coverage and simultaneously increase the attached gingiva.

Written informed consent was obtained from the patient after all treatment procedures had been fully explained.

\section{SURGICAL PROCEDURE}

After local anesthesia and intraoral disinfection with $0.2 \%$ chlorhexidine mouthrinse, the exposed root surfaces were planed thoroughly and gently irrigated. Recipient sites were prepared by giving a horizontal incision at the level of CEJ extending mesially and distally terminating short of the line angles of adjacent teeth. From here vertical incisions were made extending well into the alveolar mucosa, so that they were $3 \mathrm{~mm}$ beyond the apical extent of the recession defects (Figure 3 and Figure 4 ). Firm connective tissue

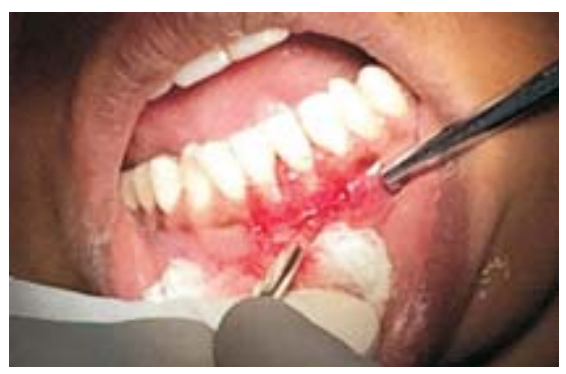

Figure 3: Preparation of recipient site 


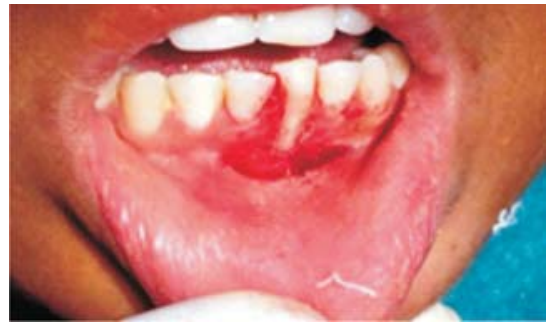

Figure 4: Preparation of the recipient site

beds were prepared by removing all the epithelium and muscular tissue. Root biomodification with tetracycline hydrochloride $50 \mathrm{mg} / \mathrm{ml}$ for 3 minutes was then performed in both the cases.

The size of donor tissue needed was accurately determined by using a foil template. Left side of palate between first and second premolars was selected to harvest the donor tissue. Horizontal incisions, 1.5 to $2 \mathrm{~mm}$ in depth were made at least $2 \mathrm{~mm}$ away from the gingival margin of premolars. Grafts were carefully lifted and separated from the palate (Figure 5 and

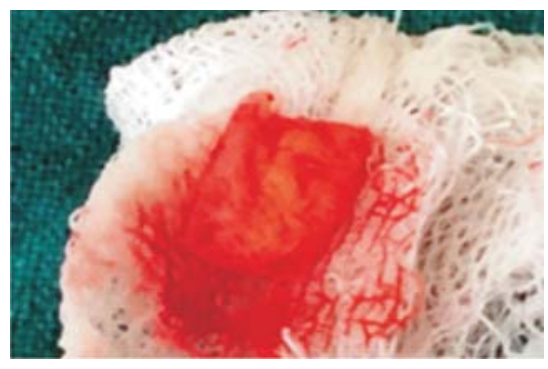

Figure 5: Free gingival graft

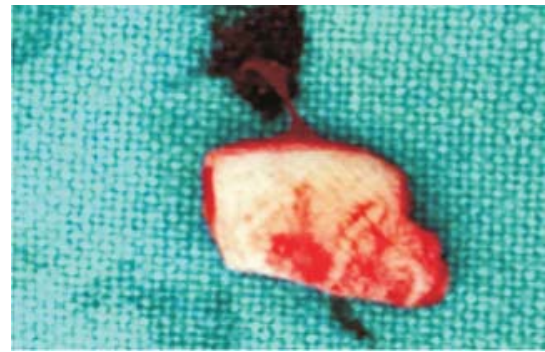

Figure 6: Free gingival graft

Figure 6). Great care was taken to ensure uniform thickness of the grafts. Any glandular or fatty tissue was removed. Grafts were placed on the recipient beds and sutured with interrupted sutures (5-0 Vicryl resorbable). Vertical sling sutures were given for the close adaptation of grafts. The grafted tissue was compressed for $5 \mathrm{~min}$ on the recipient bed. After this periodontal pack was placed to protect the surgical site (Figure 7 and Figure 8 ).

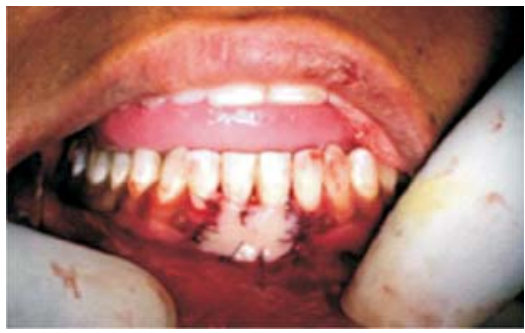

Figure 7: Free gingival graft sutured

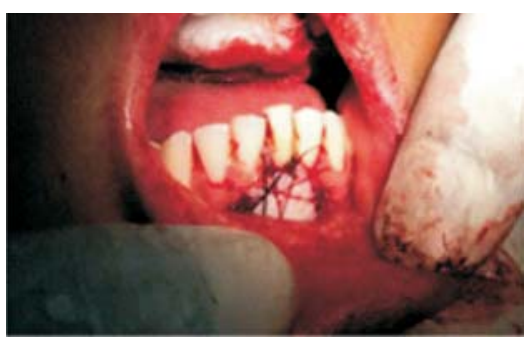

Figure 8: Free gingival graft sutured

A new method of placing the pack was developed in these cases in which periodontal pack was stabilized with the help of tin foil and sling sutures without using any retention plate (Figure 9 and Figure 10).

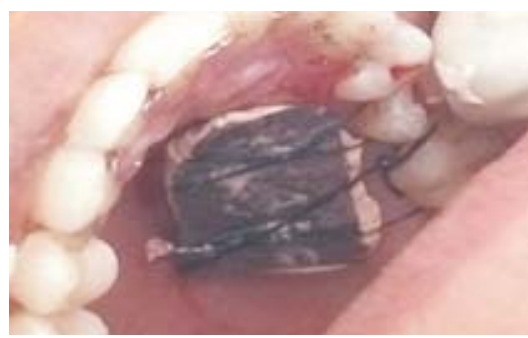

Figure 9: Donor site sutured

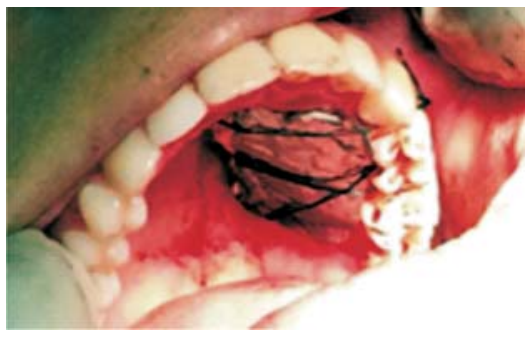

Figure 10: Donor site sutured 
Slightly larger tin foil than the palatal donor site wound was cut. The periodontal pack along with tinfoil was secured on the donor site with the help of 2 sling sutures.

The patient was prescribed amoxicillin 500mg and $400 \mathrm{mg}$ of ibuprofen thrice daily for 5 days and instructed to rinse twice daily with $0.2 \%$ chlorhexidine rinse for 6 weeks postoperatively. Surgical site was irrigated with normal saline and sutures were removed 10 days after the surgery and home care instructions were given. The healing of palatal wound was satisfactory; patient did not complain of any discomfort. The patient was instructed to use a ultra soft tooth brush with a roll technique followed by a 60 second rinse with chlorhexidine digluconate for 6 weeks.

\section{RESULTS}

The cases were evaluated after every 15 days for follow up. Figure 11 and Figure 12 show complete healing of

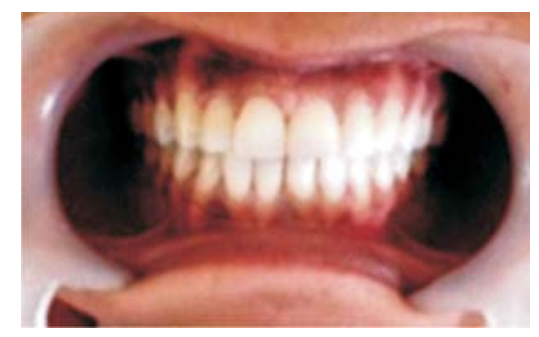

Figure 11: Postoperative view (3 months)

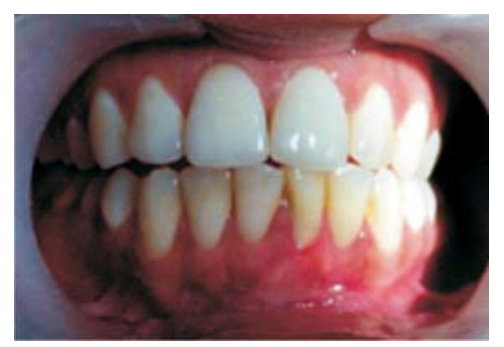

Figure 12: Postoperative view (3months)

free gingival autografts 3 months postoperatively. Probing depth at the midbuccal site was less than $1 \mathrm{~mm}$ apical to the CEJ, and the amount of attached gingiva was adequate. Both patients were followed 12 months postoperatively and complete tissue healing was achieved. The patients reported that the final esthetic results were acceptable to them.

\section{DISCUSSION}

Gingival recession usually creates an esthetical problem and fear of tooth loss due to progressing destruction, and it may also be associated with dentin hypersensitivity and/or root caries, and cervical wear. Coverage of denuded roots has become one of the most challenging procedures in periodontal mucogingival surgery. Although all periodontal plastic surgery procedures are effective in reducing the extent of exposed root surface, with a concomitant gain in Clinical attachment level (CAL) and increase in width of keratinized tissue but from an esthetic and subjective point of view, complete root coverage represents the desired treatment goal. Predictability of root coverage procedures is dependent on several factors such as anatomical, surgical skills of the operator and postoperative maintenance by the patients. Complete success in treating gingival recession is obtained when the following criteria are satisfied.

1. Gingival margin is at CEJ or slightly coronal to it.

2. Sulcus depth is less than or equal to $2 \mathrm{~mm}$.

3. Presence of attached gingiva.

4. No bleeding on probing at the treated site.

Root coverage by placing free graft was first described by Sullivan and Atkins, they reported that free gingival graft offers best results in cases of shallow and narrow recession. According to them when graft is placed over recession, some amount of "bridging" can be expected because a portion of grafted tissue which is covering the root will survive by receiving circulation from the vascular portion of the recipient site.

For the healing of donor site an acrylic stent is normally made but there are some drawbacks like difficulty to wear, difficulty in chewing, speaking and dislodgement of periodontal pack. To overcome these 
drawbacks a new method of placing the pack has been developed in which periodontal pack is stabilized with the help of tin foil and sling sutures without using any retention plate. This method of protecting the donor site results in faster healing and poses no discomfort to the patient.

A summary of published studies shows that on an average, 63-86\% root coverage may be expected, depending on the treatment procedure used. ${ }^{8}$ There are many factors, which influence the degree of root coverage e.g., Patient related factors, which include maintenance of oral hygiene, method of brushing and smoking; Site related factors, like interdental periodontal support and extent of recession (complete coverage is possible only in Miller's class I and II recessions, while in III and IV, only partial coverage is possible). In addition, in class II recession, the dimension of the recession also plays an important role in degree of root coverage. Less favorable treatment outcome has been reported at sites with wide $(>3 \mathrm{~mm})$ and deep ( $>5 \mathrm{~mm}$ ) recession. ${ }^{9}$ Miller in 1987 proposed many factors for incomplete or failure of root coverage. These include improper classification of marginal tissue recession, inadequate root planing, improper root biomodification, improper preparation of recipient site, inadequate graft size and thickness, dehydration of graft, inadequate adaptation of graft to root and remaining periosteal bed, failure to stabilize the graft, excess or prolonged pressure on sutured graft, reduction of inflammation prior to grafting, trauma to graft during initial healing. ${ }^{10}$

\section{CONCLUSION}

According to Miller, root coverage procedure is quite predictable and produces patient satisfaction; it should be therapist's obligation to make patients aware of this treatment modality. Autogenous free gingival grafting is a well established mucogingival procedure for increasing the width of attached gingiva. The surgical procedure is technique sensitive and attention to the details involved in the execution of the surgery are crucial to achieve a successful and satisfying outcome.

\section{REFERENCES}

1. Wennnstrome JL. Mucogingival therapy. Annals periodontology 1996;1:671-701.

2. Lindhe J. Clinical periodontology \& implant dentistry. Ist edition 1983, 4th edition 2003, 579 .

3. Lindhe J, Karring T. Anatomy of the periodontium. In: Lindhe J, Karring T, Lang NP, ed. Clinical periodontology and implant dentistry. 3rd edn. Copenhagen: Munksgaard, 1997: 19-68.

4. Hemant G. Free soft tissue autograft in the treatment of class II gingival recession with shallow vestibule. A case report. BFUDJ 2012;3:123-126.

5. Chr. Popova. Free gingival autograft for augmentation of keratinized tissue and stabilization of gingival recessions. Journal of IMAB - Annual Proceeding (Scientific Papers) 2008, book 2 .

6. Miller PD Jr. Root coverage grafting for regeneration and aesthetics. Periodon 2000 1993;1:118-127.

7. Santosh K. Free gingival graft in the treatment of class III gingival recession with shallow vestibule. Dental practice 2010;3:12-15.

8. Wennstrom JL, PiniPrato GP. Mucogingival therapyperiodontal plastic surgery. In: Clinical Periodontology and implant dentistry. J Lindhe, N P Lang, T Karring, Eds; 4th Edn.; Blackwell Publication, Munksgaard, 2003;pp576-649.

9. PriniPrato GP, Tinti C, Vincenzi G. Guided tissue regeneration versus mucogingival surgery in the treatment of human buccal gingival recession. Jour of Periodont 1992; 63:919-928.

10. Miller Jr P. Root coverage with the free gingival graft-Factors associated with incomplete coverage. Jour of Periodont 1987; 10: 674 . 